\title{
Optimization of Alkaline Extraction and Bioactivities of Polysaccharides from Rhizome of Polygonatum odoratum
}

\author{
Yong Chen, ${ }^{1}$ Luoyi Yin, ${ }^{1}$ Xuejiao Zhang, ${ }^{1}$ Yan Wang, ${ }^{1}$ Qiuzhi Chen,, \\ Chenzhong Jin, ${ }^{1}$ Yihong $\mathrm{Hu},{ }^{1}$ and Jihua Wang ${ }^{2}$ \\ ${ }^{1}$ Department of Life Sciences, Hunan Institute of Humanities, Science and Technology, Loudi 417000, China \\ ${ }^{2}$ Crop Research Institute, Guangdong Academy of Agriculture Sciences, Guangzhou 510640, China \\ Correspondence should be addressed to Yihong Hu; huyhongwangyi@163.com
}

Received 24 March 2014; Revised 17 June 2014; Accepted 17 June 2014; Published 1 July 2014

Academic Editor: Carla R. Arciola

Copyright (C) 2014 Yong Chen et al. This is an open access article distributed under the Creative Commons Attribution License, which permits unrestricted use, distribution, and reproduction in any medium, provided the original work is properly cited.

\begin{abstract}
The present study is to explore the optimal extraction parameters, antioxidant activity, and antimicrobial activity of alkaline soluble polysaccharides from rhizome of Polygonatum odoratum. The optimal extraction parameters were determined as the following: $\mathrm{NaOH}$ concentration (A) $0.3 \mathrm{M}$, temperature (B) $80^{\circ} \mathrm{C}$, ratio of $\mathrm{NaOH}$ to solid (C) 10 -fold, and extraction time (D) $4 \mathrm{~h}$, in which ratio of $\mathrm{NaOH}$ to solid was a key factor. The order of the factors was ratio of $\mathrm{NaOH}$ to solid (fold, $\mathrm{C}$ ) > extraction temperature $\left({ }^{\circ} \mathrm{C}\right.$, B) $>\mathrm{NaOH}$ concentration $(\mathrm{M}, \mathrm{A})>$ extraction time (h, D). The monosaccharide compositions of polysaccharides from $P$. odoratum were rhamnose, mannose, xylose, and arabinose with the molecular ratio of 31.78, 31.89, 11.11, and 1.00, respectively. The reducing power, the 1, 1-diphenyl-2-picryl-hydrazil (DPPH) radical scavenging rate, the hydroxyl radicals scavenging rate, and the inhibition rate to polyunsaturated fatty acid (PUFA) peroxidation of the alkaline soluble polysaccharides from P. odoratum at $1 \mathrm{mg} / \mathrm{mL}$ were $9.81 \%, 52.84 \%, 19.22 \%$, and $19.42 \%$ of ascorbic acid at the same concentration, respectively. They also showed antimicrobial activity against pathogenic bacteria Staphylococcus aureus, Pseudomonas aeruginosa, Bacillus subtilis, and Escherichia coli.
\end{abstract}

\section{Introduction}

Polygonatum odoratum (Mill.) Druce is an edible herb mainly distributed in the Southern area of China and some other south east Asian countries [1], and it is also found to be in Russia and other Europe countries [2,3]. In particular in Hunan Province of southern China, cultivated P. odoratum is customarily called "Xiang Yuzu" by local people, and the dried rhizome is often used as a common Chinese traditional medicinal herb for removing dryness, promoting secretion, and quenching thirst [4]. It is also used as functional foods and traditional Chinese medicines for treatment of diabetes [5]. People are also accustomed to adding the powder made from its dried rhizome to noodles, teas, biscuits, and other health care products or cooking the rhizome with meats and porridges. Generally, P. odoratum is now attracting more and more attention for its healthy and medical value.
Many active compounds have been identified in $P$. odoratum such as mucous polysaccharides [6], homoisoflavanones [7], azetidine-2-carboxylic acid [5, 8], saponin [9], and steroidal compounds [10]. Among them, polysaccharides are abundant in $P$. odoratum and considered as one of the important bioactive components with functions of antitumor, antidiabetes, and antioxidation. Extraction of polysaccharides from $P$. odoratum is an important approach to further research or scale application. Tomshich et al. [11] reported extraction and purification of polysaccharides from ten medicinal plants including P. odoratum, and several reports were documented on extraction and bioactivities of polysaccharides from $P$. odoratum in recent years $[1,12]$. Generally, researches were focused on the study of extraction of neutral soluble polysaccharides from $P$. odoratum, using hot water extraction or hot water extraction assisted by physical technologies such as microwave and ultrasound, to 
TABLE 1: Optimization of alkaline extraction parameters of polysaccharides from P. odoratum.

\begin{tabular}{|c|c|c|c|c|c|}
\hline Number & $\begin{array}{c}\mathrm{NaOH} \text { concentration } \\
(\mathrm{M})\end{array}$ & $\begin{array}{c}\text { Extraction temperature } \\
\left({ }^{\circ} \mathrm{C}\right)\end{array}$ & $\begin{array}{l}\text { Ratio of } \mathrm{NaOH} \text { to solid } \\
(\mathrm{v} / \mathrm{w})\end{array}$ & $\begin{array}{c}\text { Extraction time } \\
(\mathrm{h})\end{array}$ & $\begin{array}{c}\text { Extraction yield } \\
(\%)\end{array}$ \\
\hline 1 & $1(0.3)$ & $1(60)$ & $1(10)$ & $1(1)$ & 15.11 \\
\hline 2 & 1 & $2(70)$ & $2(15)$ & $2(2)$ & 14.42 \\
\hline 3 & 1 & $3(80)$ & $3(20)$ & $3(4)$ & 13.28 \\
\hline 4 & $2(0.6)$ & 1 & 2 & 3 & 13.16 \\
\hline 5 & 2 & 2 & 3 & 1 & 8.55 \\
\hline 6 & 2 & 3 & 1 & 2 & 16.22 \\
\hline 7 & $3(0.9)$ & 1 & 3 & 2 & 5.65 \\
\hline 8 & 3 & 2 & 1 & 3 & 15.21 \\
\hline 9 & 3 & 3 & 2 & 1 & 13.43 \\
\hline$k_{1}$ & 14.27 & 11.31 & 15.51 & 12.36 & \\
\hline$k_{2}$ & 12.64 & 12.73 & 13.67 & 12.10 & \\
\hline$k_{3}$ & 11.43 & 14.31 & 9.16 & 13.96 & \\
\hline$R$ & 2.84 & 3.00 & 6.35 & 1.86 & \\
\hline
\end{tabular}

optimize the productivity of polysaccharides. Nevertheless, it should be noted that hot water extraction is often associated with lower leaching efficiency, higher extraction temperature, more time-consuming, and fewer monosaccharide compositions [13]. In our previous experiment, the highest yield of hot water extraction assisted by microwave or ultrasound from $P$. odoratum was only nearly $7 \%$, and three kinds of monosaccharides were detected, suggesting that there were plenty of polysaccharides in extraction residues insoluble in hot water. Kim et al. [14] reported that alkaline extraction polysaccharides from Korean basidiomycetes were composed of four kinds of monosaccharides and displayed antitumor activity. Liu et al. [15] reported that the extraction rate of polysaccharides by mild alkaline hydrolysis from Ganoderma lucidum was significantly higher compared with hot water extraction. But there were no reports published about the alkaline extraction of polysaccharides from P. odoratum until now.

The objective of the work reported in this paper was to improve polysaccharides yield of alkaline soluble extraction from $P$. odoratum through an orthogonal test, which explored the relationship between four selected variables and determined the optimal variable values to optimize the alkaline extraction conditions, and to further investigate the bioactivity of the alkaline soluble polysaccharides extracts.

\section{Materials and Methods}

2.1. Reagents. Ethyl mercaptan, trifluoroacetic acid (TFA), acetic anhydride, pyridine, and 1, 1-diphenyl-2-picrylhydrazil (DPPH) were from Sigma Co. (St. Louis, USA). Beef extraction peptone medium and LB medium were from Guangrui Biomart Co. (Shanghai, China). All the other chemicals and reagents used were of analytical grade.

2.2. Pretreatment of Rhizome of $P$. odoratum. Rhizome of P. odoratum was collected in August, 2013, from a natural habitat in Hunan, China, and authenticated by associate
Professor Zefa Liu, Loudi Agricultural Institute, Hunan, China. Fresh rhizome was washed, sliced to pieces, and dried at $50^{\circ} \mathrm{C}$ for $48 \mathrm{~h}$. Then the pieces were ground to powder with a grinding machine. The powder was sieved with a nylon sieve of $0.18 \mathrm{~mm}$ diameter grids. $100 \mathrm{~g}$ of the sieved powder was mixed with $300 \mathrm{~mL}$ petroleum ether and heated at $55^{\circ} \mathrm{C}$ water bath for $4 \mathrm{~h}$. After filtration, the sediment was dried at $80^{\circ} \mathrm{C}$ for $12 \mathrm{~h}$, then mixed with $80 \%$ ethyl alcohol and heated at a $65^{\circ} \mathrm{C}$ water bath for $1 \mathrm{~h}$. After filtration again, the sediment was dried at $65^{\circ} \mathrm{C}$ for $12 \mathrm{~h}$ to get powder of $P$. odoratum.

2.3. Orthogonal Array Design. According to the previous study of single variable test, four control variables were selected as follows: $\mathrm{NaOH}$ concentration (M), extraction temperature $\left({ }^{\circ} \mathrm{C}\right)$, ratio of $\mathrm{NaOH}$ to solid (v/w, fold), and extraction time (hours). The variables of extraction optimization design were as shown in Table 1. Rhizome powder $(1 \mathrm{~g})$ was used in each test according to a $\mathrm{L}_{9}\left(3^{4}\right)$ array. After finishing all the tests, the solution was filtered by vacuum, and $2 \mathrm{M} \mathrm{HCl}$ was added to it to adjust $\mathrm{pH}$ value to 7.0 and then subjected to $100 \mathrm{~mL} 95 \%$ ethyl alcohol at room temperature for $12 \mathrm{~h}$. After centrifugation at $6,000 \times \mathrm{g}$ for $10 \mathrm{~min}$, the sediment was dissolved in distilled water to determine the yield. The sediment was dried to get the crude polysaccharides and stored at room temperature until use.

2.4. Purification of Polysaccharides. $0.5 \mathrm{~g}$ of crude polysaccharides was dissolved in $5 \mathrm{~mL}$ distilled water, added to $5 \mathrm{~mL} \mathrm{10 \%} \mathrm{trichloroacetic} \mathrm{acid} \mathrm{(TCA),} \mathrm{and} \mathrm{stored} \mathrm{overnight}$ at room temperature. After centrifugation at $8,500 \times \mathrm{g}$ for $30 \mathrm{~min}$, the supernatant was treated with 1/5 volume of Sevag reagent [16]. The procedure was repeated at least for 10 times to get the purified polysaccharides. The purity of polysaccharide was determined by using a UVmini-1240 spectrophotometer (Shimadzu Co., Tokyo, Japan). The scan range was 190-350 $\mathrm{nm}$ to detect the absorbance of impurities 
caused by proteins $(280 \mathrm{~nm})$ and nucleic acids (260 nm) [17]. The purified polysaccharides were stored at $4^{\circ} \mathrm{C}$ until use.

\subsection{Polysaccharide Hydrolysis and Monosaccharide Deriva-} tization. Polysaccharide hydrolysis and derivatization were performed according to the method of Pitthard and Finch [18]. $15 \mathrm{mg}$ of the purified polysaccharides was added to a test tube with $4 \mathrm{~mL} 3 \mathrm{M}$ TFA and heated at $120^{\circ} \mathrm{C}$ to hydrolyze for $5 \mathrm{~h}$. After vacuum rotary evaporation, $2 \mathrm{~mL}$ ethyl mercaptan and $1 \mathrm{~mL}$ TFA were added, stirred for a while, and incubated for $35 \mathrm{~min}$ and then evaporated again. The mixture of $2 \mathrm{~mL}$ acetic anhydride and $2 \mathrm{~mL}$ pyridine was added and heated at $55^{\circ} \mathrm{C}$ for $4 \mathrm{~h}$. This solution of monosaccharide derivatives was used directly for GC-MS analysis.

2.6. GC-MS Analysis. GC-MS detection wascarried out according to Chunsriimyatav et al. [19], using a QP2010 SE gas chromatography-mass spectrometer (Shimadzu Co., Tokyo, Japan) with a HP-5 ms id $30 \times 0.32 \mathrm{~mm}$ fused-silica column coated with df $0.25 \mu \mathrm{m}$ film (Agilent Technologies, California, Palo Alto, USA). The split-splitless injector temperature was $260^{\circ} \mathrm{C}$. The chromatographic procedures were as follows: initial temperature $80^{\circ} \mathrm{C}$ for $2 \mathrm{~min}$, up to $210^{\circ} \mathrm{C}$ at $1^{\circ} \mathrm{C} / \mathrm{min}$, then up to $280^{\circ} \mathrm{C}$ at $25^{\circ} \mathrm{C} / \mathrm{min}$, and kept at $280^{\circ} \mathrm{C}$ for $6 \mathrm{~min}$. Helium (99.999\%) was used as a carrier at $1 \mathrm{~mL} / \mathrm{min}$. Electron impact ionisation was $70 \mathrm{eV}$ with $1.5 \mathrm{scans} / \mathrm{s}$ at range of $\mathrm{m} / z$ $35-600$, and the source temperature was $220^{\circ} \mathrm{C}$.

\subsection{Antioxidant Activity Determination}

2.7.1. Reducing Power Assay. The reducing power of the polysaccharides was determined according to the method of Juntachote and Berghofer [20]. 0.5 mL 0.2 M phosphate buffer ( $\mathrm{pH}$ 6.6) and $1.5 \mathrm{~mL} 0.3 \% \mathrm{~K}_{3} \mathrm{Fe}(\mathrm{CN})_{6}$ were added to a test tube and mixed with polysaccharides $(1-10 \mathrm{mg} / \mathrm{mL})$. The solution was incubated at $50^{\circ} \mathrm{C}$ for $20 \mathrm{~min}$, then $1 \mathrm{~mL}$ $10 \%$ TCA was added, and centrifuged at 3,000 $\times \mathrm{g}$ for $10 \mathrm{~min}$. $2 \mathrm{~mL}$ of the supernatant was mixed with $0.5 \mathrm{~mL} 0.3 \% \mathrm{FeCl}_{3}$ to measure $700 \mathrm{~nm}$ absorbance after $10 \mathrm{~min}$.

2.7.2. DPPH Radical Scavenging Rate. Free radical scavenging rate of the polysaccharides was determined according to the method of Chen et al. [21] and Ulbin-Figlewicz et al. [22]. $2 \mathrm{~mL}$ of $0.03 \mathrm{mM}$ fresh-prepared DPPH-ethanol solution was mixed with $0.2 \mathrm{~mL}$ of the polysaccharides $(1-10 \mathrm{mg} / \mathrm{mL})$. The reaction mixture was stirred and immediately incubated at $25^{\circ} \mathrm{C}$ for $15 \mathrm{~min}$. The reduction of the $\mathrm{DPPH}$ free radicals was determined at $517 \mathrm{~nm}$ absorbance.

2.7.3. Hydroxyl Radical Scavenging Rate. Hydroxyl radical scavenging rate of the polysaccharides was determined according to Li et al. [23] with minor modification. $0.1 \mathrm{M} \mathrm{pH}$ 7.4 phosphate buffer was used as blank. $10 \mathrm{~mL}$ reaction mixture contained $5 \mathrm{~mL} 0.2 \mathrm{M} \mathrm{pH} 7.4$ phosphate buffer, $0.6 \mathrm{~mL}$ $5 \mathrm{mM} \mathrm{1,10-phenanthroline} \mathrm{monohydrate,} 0.4 \mathrm{~mL} 7.5 \mathrm{mM}$ $\mathrm{FeSO}_{4}, 0.2 \mathrm{~mL} 30 \% \mathrm{H}_{2} \mathrm{O}_{2}, 2.8 \mathrm{~mL}$ distilled water, and $1.0 \mathrm{~mL}$ different concentration of polysaccharides $(1-10 \mathrm{mg} / \mathrm{mL})$. The reaction mixture was stirred and immediately incubated at $37^{\circ} \mathrm{C}$ for $40 \mathrm{~min}$. Absorbance was measured at $510 \mathrm{~nm}$, and the hydroxyl radical scavenging rate was calculated as the following equation:

$$
\text { Scavenging rate }(\%)=\frac{\left[A_{\text {sample }}-A_{\text {damage }}\right]}{\left[A_{\text {nondamage }}-A_{\text {damage }}\right]},
$$

where $A_{\text {sample }}$ was absorbance of mixture containing polysaccharides and $\mathrm{H}_{2} \mathrm{O}_{2} ; A_{\text {damage }}$ was absorbance of mixture containing $\mathrm{H}_{2} \mathrm{O}_{2} ; A_{\text {nondamage }}$ was absorbance of mixture containing polysaccharides.

2.7.4. Inhibition Rate of Peroxidation of Polyunsaturated Fatty Acid from Lipoprotein. Inhibition rate of polyunsaturated fatty acid (PUFA) peroxidation from lipoprotein was determined according to Zhang et al. [24]. Yolk suspension was prepared with addition of fresh egg yolk to $0.1 \mathrm{M} \mathrm{pH} 7.4$ phosphate buffer $(\mathrm{v} / \mathrm{v}=1 / 25) .0 .2 \mathrm{~mL}$ yolk suspension was mixed with $0.1 \mathrm{~mL}$ different concentration of polysaccharides

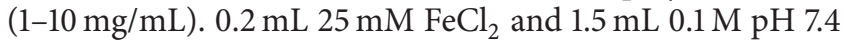
phosphate buffer were added to the mixture and incubated at $37^{\circ} \mathrm{C}$ for $15 \mathrm{~min}$ with continuous vibration. And then $0.5 \mathrm{~mL}$ $20 \%$ TCA was added to the mixture and centrifuged at $5,000 \times \mathrm{g}$ for $10 \mathrm{~min} .2 \mathrm{~mL}$ of the supernatant was added with $1 \mathrm{~mL} 0.8 \%$ thiobarbituric acid, and the solution was incubated at $75^{\circ} \mathrm{C}$ for $10 \mathrm{~min}$. After cooling to room temperature, absorbance was determined at $532 \mathrm{~nm}$. The inhibition rate was calculated using the following equation:

$$
\text { Inhibition rate } \%=\frac{\left[A_{\text {control }}-A_{\text {sample }}\right]}{A_{\text {control }}},
$$

where $A_{\text {control }}$ was absorbance of mixture using the same volume of distilled water instead of polysaccharides; $A_{\text {sample }}$ was absorbance of mixture containing polysaccharides.

2.8. Antimicrobial Activity. The antimicrobial activity was determined following the method of Lipipun et al. [25] with modification. Beef extraction peptone medium and broth medium were prepared and sterilized in an autoclave. Four bacterial strains Staphylococcus aureus, Pseudomonas aeruginosa, Bacillus subtilis, and Escherichia coli were individually incubated on $\mathrm{LB}$ medium at $37^{\circ} \mathrm{C}$ for $24 \mathrm{~h}$, and bacterial plaques were selected and suspended to $9 \mathrm{~mL}$ sterile saline to prepare bacterial suspension at concentration of $1 \times 10^{8} \mathrm{cfu} / \mathrm{mL}$. $0.2 \mathrm{~mL}$ bacterial suspension was uniformly coated on beef extraction peptone medium of the petri dishes. Plates of sterile filter paper, $6 \mathrm{~mm}$ in diameter each, were soaked in different concentration of polysaccharides $(1-10 \mathrm{mg} / \mathrm{mL})$ and dried and then were placed into the petri dishes to incubate at $37^{\circ} \mathrm{C}$ for $24 \mathrm{~h}$. Result was calculated by measuring the zone of inhibition in millimeters.

2.9. Data Analysis. All experiments were repeated at least three times and the results were expressed as mean \pm standard error. Statistical analyses were performed using SPSS13.0, and the data were analyzed using one-way ANOVA followed by LSD test $(P<0.05)$. 


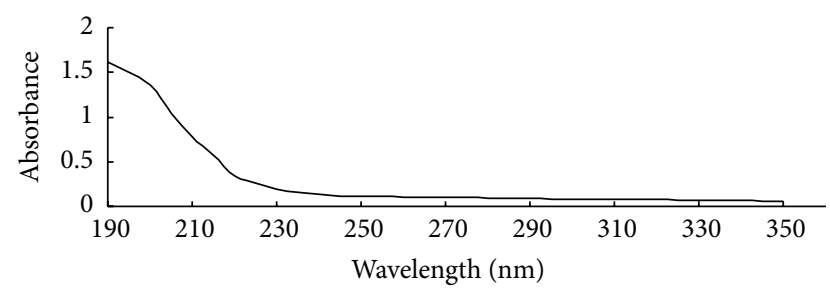

FIGURE 1: UV spectrophotometry analysis of the purity of alkaline soluble polysaccharides from $P$. odoratum.

\section{Results and Discussion}

3.1. Alkaline Extraction of Polysaccharides. The factorial design of four factors and three levels was carried out to evaluate the extraction efficiency of polysaccharides. The four factors were $\mathrm{NaOH}$ concentration (A), extraction temperature (B), ratio of $\mathrm{NaOH}$ to solid (C), and extraction time (D). Therefore, nine experiments of $\mathrm{L}_{9}\left(3^{4}\right)$ array were performed, and factors and levels were depicted in Table 1. The results showed that ratio of $\mathrm{NaOH}$ to solid (C) was more significant ( $R=6.35$ ) than the other factors, and the order of the factors was found to be ratio of $\mathrm{NaOH}$ to solid (fold, C) $>$ extraction temperature $\left({ }^{\circ} \mathrm{C}, \mathrm{B}\right)>\mathrm{NaOH}$ concentration $(\mathrm{M}, \mathrm{A})$ $>$ extraction time (h, D). The optimal extraction parameters were $\mathrm{A} 1, \mathrm{~B} 3, \mathrm{C} 1$, and $\mathrm{D} 3$, namely, $\mathrm{NaOH}$ concentration $0.3 \mathrm{M}$, extraction temperature $80^{\circ} \mathrm{C}$, ratio of $\mathrm{NaOH}$ to solid 10 fold, and extraction time $4 \mathrm{~h}$, respectively. Under the optimal condition, the extraction was repeated and the actual yield was $17.28 \%(n=3)$. Jiang et al. [12] reported that the yield of polysaccharides using hot water extraction (extraction times $=4$ ) was about $14.2 \%$, and Lan et al. [1] reported that its yield using hot water extraction assisted by ultrasound (extraction times $=3$ ) was $15.15 \%$. The yield of alkaline extraction from $P$. odoratum was higher than that of hot water extraction. In addition, this method was much more time-saving because it was needed to be extracted only once.

3.2. GC-MS Analysis of Polysaccharides. TCA and Sevag reagent were employed to get rid of impurities such as proteins and nucleic acids before GC-MS analysis. As shown in Figure 1, there were no absorption peaks at $260 \mathrm{~nm}$ and $280 \mathrm{~nm}$, with the absorbance only 0.106 and 0.095 , respectively, and an obvious absorbance of polysaccharides at $190 \mathrm{~nm}$ was observed 1.621, showing that the polysaccharides were free of impurities such as proteins and nucleic acids and were reliable for further analysis [26].

The polysaccharides were hydrolyzed by TFA and derived by "ethyl mercaptan-acetic anhydride-pyridine" method as mentioned before. The derivatives were used to determine the monosaccharide compositions, because monosaccharide in this condition was converted to volatile substances and easy to be detected by GC-MS [18]. Lan et al. [1] determined three kinds of monosaccharides from neutral soluble polysaccharides in $P$. odoratum by GC, which were fucose, mannose, and galactose with the molecular ratio of $4.72,3.90$, and 1.00 , respectively. In our experiment, monosaccharide compositions of alkaline soluble polysaccharides in $P$. odoratum

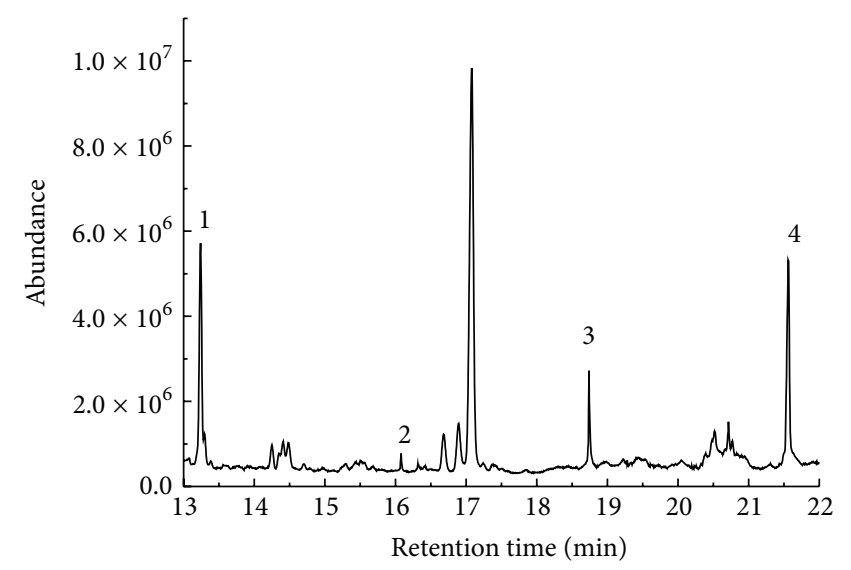

FIgURE 2: Total ion chromatogram of the peracetylated diethyl dithioacetals of the hydrolysate derivatives of alkaline soluble polysaccharides from $P$. odoratum (1: mannose, 2: arabinose, 3: xylose, and 4: rhamnose).

TABLE 2: Molecular ratio of monosaccharide mixture from alkaline soluble polysaccharides from P. odoratum.

\begin{tabular}{lccc}
\hline Monosaccharide & Formula & $\begin{array}{c}\text { Retention } \\
\text { time (min) }\end{array}$ & $\begin{array}{c}\text { Molecular } \\
\text { ratio }\end{array}$ \\
\hline Rhamnose & $\mathrm{C}_{18} \mathrm{H}_{30} \mathrm{O}_{8} \mathrm{~S}_{2}$ & 21.56 & 31.78 \\
Mannose & $\mathrm{C}_{20} \mathrm{H}_{32} \mathrm{O}_{10} \mathrm{~S}_{2}$ & 13.24 & 31.89 \\
Xylose & $\mathrm{C}_{17} \mathrm{H}_{28} \mathrm{O}_{8} \mathrm{~S}_{2}$ & 18.74 & 11.11 \\
Arabinose & $\mathrm{C}_{17} \mathrm{H}_{28} \mathrm{O}_{8} \mathrm{~S}_{2}$ & 16.08 & 1.00 \\
\hline
\end{tabular}

were detected by GC-MS (Figure 2), and the compositions consisted of four kinds of monosaccharide as rhamnose, mannose, xylose, and arabinose with the molecular ratio of nearly $31.78,31.89,11.11$, and 1.00 , respectively (Table 2). The results showed that alkaline soluble polysaccharides differed from neutral soluble polysaccharides in compositions. Tomshich et al. [11] reported that neutral soluble polysaccharides from $P$. odoratum roots with additional ammonium oxalate and $\mathrm{NaOH}$ purification steps consisted of arabinose, mannose, and rhamnose with the molecular ratio of 3.38, 3.31, and 1.00 , respectively, which were similar to these alkaline soluble polysaccharides in compositions. In addition, Lan et al. [27] reported that two types of dietary Polygonatum fibers DFPS and DFDS extracted by $\mathrm{NaOH}$ consisted of arabinose, xylose, sorbose, mannose, and galactose with different molecular ratios, which were also similar to the alkaline soluble polysaccharides in compositions. It was indicated that, during the processing method, $\mathrm{NaOH}$ might change the chemical structure of polysaccharides.

3.3. Antioxidant Activity Analysis. The reducing power is frequently used to evaluate the electron donating ability, and there is a close correlation between the antioxidant activity and the reducing power of polysaccharides. Therefore, researchers often use the reducing power as an important standard for evaluating the antioxidant ability [28, 29]. 


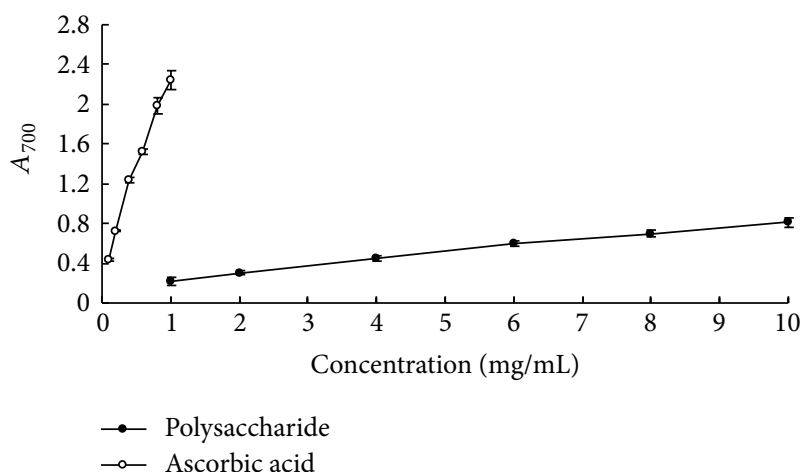

Figure 3: Reducing power of alkaline soluble polysaccharides from P. odoratum and ascorbic acid.

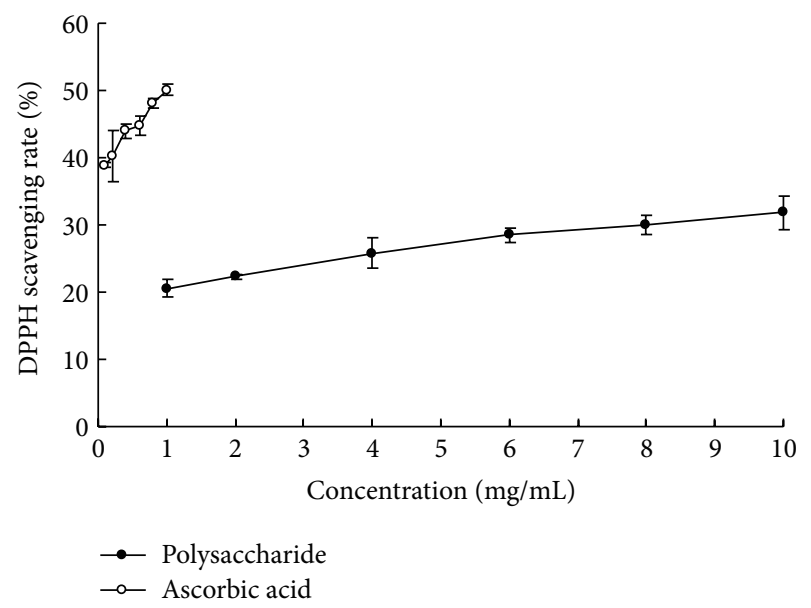

FIGURE 4: DPPH radical scavenging rate of alkaline soluble polysaccharides from $P$. odoratum and ascorbic acid.

Commonly, the reduction of three-valent iron ion to twovalent iron ion is determined at the absorbance $700 \mathrm{~nm}$, and ascorbic acid is used as control in assay of reduction ability. As shown in Figure 3, the reducing power of alkaline solublepolysaccharides in $P$. odoratum increased as the concentration increased. By comparison, ascorbic acid showed greater reducing power than polysaccharides. The reducing power of $1 \mathrm{mg} / \mathrm{mL}$ polysaccharides was $0.22 \pm$ 0.037 , about $9.81 \%$ of the activity of ascorbic acid at the same concentration, while the reducing power of $1 \mathrm{mg} / \mathrm{mL}$ ascorbic acid reached $2.242 \pm 0.100$. The results indicated that reductone and hydroxide groups of polysaccharides could play a role as electron donors [30]. Nevertheless, the reducing power of polysaccharides was apparently lower than those of ascorbic acid and homoisoflavanones from $P$. odoratum [31], indicating that alkaline soluble polysaccharides from $P$. odoratum were weak electron donors.

$\mathrm{DPPH}$ radical scavenging is a convenient method to rapidly assess the antioxidant ability of biological extracts, because DPPH is a kind of stable nitrogen-centered free radical [32]. It is based on ethanolic DPPH solution from mauve to yellow due to electron donation. Gui and Ryu [28] reported that polysaccharides from plant showed high

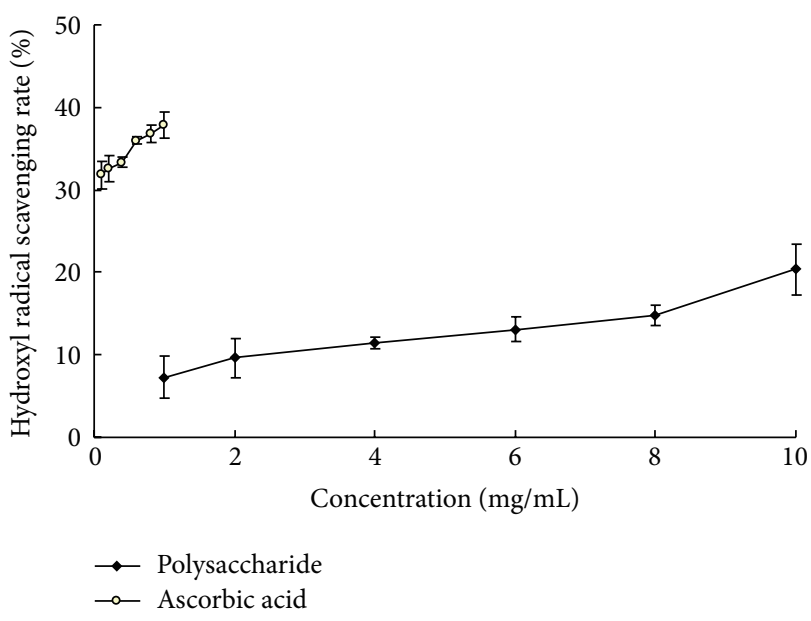

FIGURE 5: Hydroxyl radical scavenging rate of alkaline soluble polysaccharides from $P$. odoratum and ascorbic acid.

DPPH scavenging activity. As depicted in Figure 4, a considerable scavenging rate of alkaline soluble polysaccharides in $P$. odoratum was observed. The DPPH scavenging rate of $1 \mathrm{mg} / \mathrm{mL}$ polysaccharides was $20.53 \%$, about $40.97 \%$ of the activity of ascorbic acid at the same concentration, while the scavenging rate of $1 \mathrm{mg} / \mathrm{mL}$ ascorbic acid was $50.11 \%$. The results indicated that alkaline soluble polysaccharides in $P$. odoratum were good DPPH scavengers.

Hydroxyl radicals are the most toxic and active among free radicals. Generally, the scavenging ability of polysaccharides is often evaluated through Fenton reaction [33]. As shown in Figure 5, the hydroxyl radical scavenging rate of alkaline soluble polysaccharides in P. odoratum showed an ascending trend as the concentration of polysaccharides increased, but the scavenging rate was only $7.27 \%$ at $1 \mathrm{mg} / \mathrm{mL}$. Ascorbic acid is a known strong scavenging agent of hydroxyl radicals, and its scavenging rate at the same concentration was up to $37.82 \%$, while the scavenging rate of $1 \mathrm{mg} / \mathrm{mL}$ polysaccharides was only $19.22 \%$ of ascorbic acid at the same concentration. The results showed that alkaline soluble polysaccharides in $P$. odoratum were weak hydroxyl radical scavengers.

PUFA plays an important role in maintaining cell transport system and enzyme activity, and it is easy to be peroxidized [34]. The protective ability of PUFA is used to evaluate the antioxidant activities of polysaccharides, because PUFA from yolk lipoprotein induced by iron is inhibited by polysaccharides. Thus, the antioxidant activity of polysaccharides is correlated with this inhibition rate. The system is applied to determine the activity of effective ingredients of Chinese traditional medicine [24]. As depicted in Figure 6, the inhibition rate of PUFA peroxidation of alkaline soluble polysaccharides in $P$. odoratum was in an ascending trend when the polysaccharides concentration was increased from 1 to $10 \mathrm{mg} / \mathrm{mL}$, but the inhibition rate of polysaccharides was lower compared with ascorbic acid. The inhibition rate of $1 \mathrm{mg} / \mathrm{mL}$ polysaccharides was only $19.42 \%$ of ascorbic acid at the same concentration. 
TABLE 3: Antimicrobial activity of alkaline soluble polysaccharides from P. odoratum.

\begin{tabular}{|c|c|c|c|c|}
\hline \multirow{2}{*}{ Polysaccharide concentration (mg/mL) } & \multicolumn{4}{|c|}{ Diameter of inhibition zone } \\
\hline & S. aureus & P. aeruginosa & B. subtilis & E. coli \\
\hline Blank & - & - & - & - \\
\hline 1.25 & $7.30 \pm 1.18$ & - & - & - \\
\hline 2.50 & $8.33 \pm 1.53^{\mathrm{a}}$ & $6.81 \pm 1.27^{\mathrm{c}}$ & - & $7.45 \pm 1.32^{\mathrm{ab}}$ \\
\hline 5.0 & $10.38 \pm 1.80^{\mathrm{a}}$ & $7.96 \pm 0.79^{\mathrm{b}}$ & $6.71 \pm 0.87^{\mathrm{c}}$ & $7.73 \pm 1.22^{\mathrm{b}}$ \\
\hline 7.5 & $14.32 \pm 1.05^{\mathrm{a}}$ & $9.13 \pm 0.83^{\mathrm{b}}$ & $8.87 \pm 1.89^{\mathrm{b}}$ & $9.38 \pm 1.56^{\mathrm{b}}$ \\
\hline 10.0 & $14.93 \pm 1.35^{\mathrm{a}}$ & $11.58 \pm 2.21^{\mathrm{bc}}$ & $10.98 \pm 2.15^{\mathrm{c}}$ & $12.43 \pm 1.42^{\mathrm{b}}$ \\
\hline
\end{tabular}

All results were presented as the means of three experiments. Values in the same lines with different letters were significantly different $(P<0.05)$.

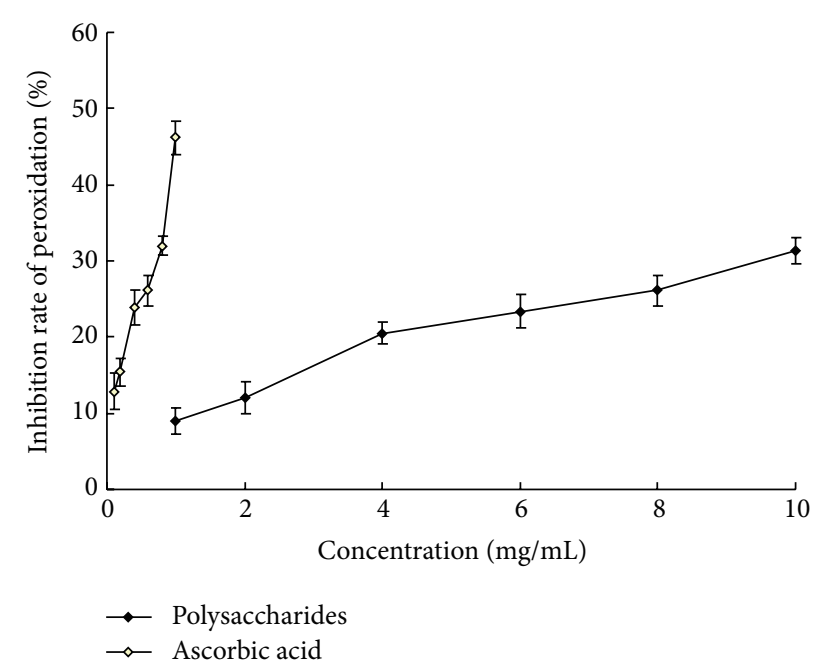

FIGURE 6: Inhibition rate of PUFA peroxidation of alkaline soluble polysaccharides from $P$. odoratum and ascorbic acid.

3.4. Antimicrobial Activity. Research on antimicrobial activity of polysaccharides may contribute to valuable new information for future antibiotic development. Many authors have previously investigated the antimicrobial activity of polysaccharides from a wide range of organisms such as seaweeds, mushroom, and durian fruit $[25,35,36]$. In P. odoratum, homoisoflavanone, triterpenoids, steroidal saponins, and volatile compounds such as long chain fatty alcohols and phenolic compound were identified and isolated, and these compounds showed high antimicrobial activity against bacteria or fungi [19]. In this study, the highest inhibition zone of $14.93 \pm 1.35 \mathrm{~mm}$ was observed against $S$. aureus, and the lowest inhibition zone of $10.98 \pm 2.15 \mathrm{~mm}$ was observed against B. subtilis at concentration of $10.0 \mathrm{mg} / \mathrm{mL}$ of alkaline soluble polysaccharides. The extracts of alkaline soluble polysaccharides from $P$. odoratum showed antimicrobial activity against all the tested pathogenic bacteria (Table 3 ). The results enforced the idea that $P$. odoratum is a potential source to be considered for substances in new drug development.

\section{Conclusion}

In the present study, an orthogonal test was carried out to optimize extraction of alkaline soluble polysaccharides from $P$. odoratum. The optimal parameters were $\mathrm{NaOH}$ concentration $0.3 \mathrm{M}$, temperature $80^{\circ} \mathrm{C}$, ratio of $\mathrm{NaOH}$ to solid 10 -fold, and extraction time $4 \mathrm{~h}$, and the actual yield was $17.28 \%$, in which ratio of $\mathrm{NaOH}$ to solid (C) was more significant $(R=6.35)$ than the other factors, and the order of the factors was found to be ratio of $\mathrm{NaOH}$ to solid (fold, C) $>$ extraction temperature $\left({ }^{\circ} \mathrm{C}, \mathrm{B}\right)>\mathrm{NaOH}$ concentration $(\mathrm{M}, \mathrm{A})>$ extraction time $(\mathrm{h}, \mathrm{D})$. The alkaline soluble polysaccharides consisted of four monosaccharide compositions, which were rhamnose, mannose, xylose, and arabinose with the molecular ratio of $31.78,31.89,11.11$, and 1.00 , respectively. They showed antioxidant activity such as DPPH radical scavenging ability, hydroxyl radical scavenging ability, hydroxyl radical scavenging ability, and PUFA protective ability, but the antioxidant activity was lower compared with the same concentration of ascorbic acid. Moreover, the alkaline soluble polysaccharides from $P$. odoratum showed antimicrobial activity against $S$. aureus, $P$. aeruginosa, $B$. subtilis, and E. coli.

\section{Conflict of Interests}

The authors declare that there is no conflict of interests regarding the publication of this paper.

\section{Acknowledgment}

This work was a project supported by Scientific Research Fund of Hunan Provincial Education Department (11A059, 12B070).

\section{References}

[1] G. Lan, H. Chen, Z. Wang, W. Zhang, and L. Zhang, "Extraction of Polygonatum odoratum polysaccharides using response surface methodology and preparation of a compound beverage," Carbohydrate Polymers, vol. 86, no. 3, pp. 1175-1180, 2011.

[2] M. Gu, Y. Zhang, S. Fan, X. Ding, G. Ji, and C. Huang, "Extracts of Rhizoma Polygonati Odorati prevent high-fat diet-induced metabolic disorder in C57BL/6 mice," Plos ONE, vol. 8, no. 11, Article ID e81724, 2013.

[3] W. Wujisguleng, Y. Liu, and C. Long, "Ethnobotanical review of food uses of Polygonatum (Convallariaceae) in China," Acta Societatis Botanicorum Poloniae, vol. 81, no. 4, pp. 239-244, 2012. 
[4] X. Shu, J. Lv, J. Tao, G. Li, H. Li, and N. Ma, "Antihyperglycemic effects of total flavonoids from Polygonatum odoratum in STZ and alloxan-induced diabetic rats," Journal of Ethnopharmacology, vol. 124, no. 3, pp. 539-543, 2009.

[5] S. Baek, J. G. Lee, S. Y. Park et al., "Gas chromatographic determination of azetidine-2-carboxylic acid in rhizomes of Polygonatum sibiricum and Polygonatum odoratum," Journal of Food Composition and Analysis, vol. 25, no. 2, pp. 137-141, 2012.

[6] M. Tomoda, Y. Yoshida, H. Tanaka, and M. Uno, "Plant mucilages. II. Isolation and characterization of a mucous polysaccharide, "Odoratan," from Polygonatum odoratum var. japonicum rhizomes," Chemical and Pharmaceutical Bulletin, vol. 19, no. 10, pp. 2173-2177, 1971.

[7] Y. Qian, J. Y. Liang, W. Qu, and Y. Y. Che, "Two new homoisoflavanones from Polygonatum odoratum (Mill.) Druce," Chinese Chemical Letters, vol. 21, no. 6, pp. 706-708, 2010.

[8] J. S . Kim, S. C. Lee, B. Lee, and K. Y. Cho, "Biological activity of 1-2-azetidinecarboxylic acid, isolated from Polygonatum odoratum var. pluriflorum, against several algae," Aquatic Botany, vol. 85, no. 1, pp. 1-6, 2006.

[9] Y. Deng, K. He, X. Ye et al., "Saponin rich fractions from Polygonatum odoratum (Mill.) Druce with more potential hypoglycemic effects," Journal of Ethnopharmacology, vol. 141, no. 1, pp. 228-233, 2012.

[10] M. Sugiyama, K. Nakano, T. Tomimatsu, and T. Nohara, "Five steroidal components from the rhizomes of Polygonatum odoratum var Pluriflorum," Chemical and Pharmaceutical Bulletin, vol. 32, no. 4, pp. 1365-1372, 1984.

[11] S. V. Tomshich, N. A. Komandrova, E. N. Kalmykova et al., "Biologically active polysaccharides from medicinal plants of the Far East," Chemistry of Natural Compounds, vol. 33, no. 2, pp. 146-149, 1997.

[12] Q. Jiang, Y. Lv, W. Dai, X. Miao, and D. Zhong, "Extraction and bioactivity of Polygonatum odoratum polysaccharides," International Journal of Biological Macromolecules, vol. 54, no. 1, pp. 131-135, 2013.

[13] S. Huang, J. Li, Z. Wang, H. Pan, J. Che, and Z. Ning, "Optimization of alkaline extraction of polysaccharides from Ganoderma lucidum and their effect on immune function in mice," Molecules, vol. 15, no. 5, pp. 3694-3708, 2010.

[14] B. K. Kim, H. S. Chung, K. S. Chung, and M. S. Yang, "Studies on atineoplastic components of Korean basidiomycetes," Korean Journal of Mycology, vol. 8, pp. 107-113, 1980.

[15] G. Liu, Y. Zhao, X. Wang, and C. Zhu, "Response surface methodology for optimization of polysaccharides extraction by mild alkaline hydrolysis from fruiting body of medicinal mushroom, Ganoderma lucidum," Journal of Medicinal Plants Research, vol. 5, no. 10, pp. 2064-2070, 2011.

[16] H. Tong, Z. Liang, and G. Wang, "Structural characterization and hypoglycemic activity of a polysaccharide isolated from the fruit of Physalis alkekengi L.," Carbohydrate Polymers, vol. 71, no. 2, pp. 316-323, 2008.

[17] L. Feng, X. Jia, F. Shi, and Y. Chen, "Identification of two polysaccharides from Prunella vulgaris L. and evaluation on their anti-lung adenocarcinoma activity," Molecules, vol. 15, no. 8, pp. 5093-5103, 2010.

[18] V. Pitthard and P. Finch, "GC-MS analysis of monosaccharide mixtures as their diethyldithioacetal derivatives: application to plant gums used in art works," Chromatographia Supplement, vol. 53, no. 1, pp. S317-S321, 2001.
[19] G. Chunsriimyatav, M. Dumaa, D. Regdel, Y. Gerelt-Od, and D. Selengea, "GC-MS analysis of some bioactive volatile constituents from aerial parts of Polygonatum odoratum (Mill. Druce)," International Journal of Current Science, vol. 7, pp. 142145, 2013.

[20] T. Juntachote and E. Berghofer, "Antioxidative properties and stability of ethanolic extracts of Holy basil and Galangal," Food Chemistry, vol. 92, no. 2, pp. 193-202, 2005.

[21] J. Chen, J. Yeh, P. Chen, and C. Hsu, "Phenolic content and DPPH radical scavenging activity of yam-containing surimi gels influenced by salt and heating," Asian Journal of Health and Information Sciences, vol. 2, no. 1-4, pp. 1-11, 2007.

[22] N. Ulbin-Figlewicz, A. Zimoch, and A. Jarmoluk, "Plant extracts as components of edible antimicrobial protective coatings," Czech Journal of Food Sciences, vol. 31, no. 6, pp. 596-600, 2013.

[23] C. Li, X. Li, H. Li, S. Guo, and X. Zhu, "Chemical constituents and antioxidant activities of waste liquid extract from Apostichopus japonicus Selenka processing," Chinese Journal of Oceanology and Limnology, vol. 31, no. 4, pp. 850-859, 2013.

[24] E. Zhang, L. Yu, Y. Zhou, and X. Xiao, "Studies on the peroxidation of polyunsaturated fatty acid from lipoprotein induced by iron and the evaluation of the anti-oxidative activity of some natural products," Acta Biochimica et Biophysica Sinica, vol. 28, no. 2, pp. 221-222, 1996.

[25] V. Lipipun, N. Nantawanit, and S. Pongsamart, "Antimicrobial activity (in vitro) of polysaccharide gel from durian fruit-hulls," Songklanakarin Journal of Science and Technology, vol. 24, no. 1, pp. 31-38, 2002.

[26] P. Zou, X. Yang, W. Huang et al., "Characterization and bioactivity of polysaccharides obtained from pine cones of Pinus koraiensis by graded ethanol precipitation," Molecules, vol. 18, no. 8, pp. 9933-9948, 2013.

[27] G. Lan, H. Chen, S. Chen, and J. Tian, "Chemical composition and physicochemical properties of dietary fiber from Polygonatum odoratum as affected by different processing methods," Food Research International, vol. 49, no. 1, pp. 406-410, 2012.

[28] Y. Gui and G. H. Ryu, "The effect of extrusion conditions on the acidic polysaccharide, ginsenoside contents and antioxidant properties of extruded Korean red ginseng," Journal of Ginseng Research, vol. 37, no. 2, pp. 219-226, 2013.

[29] K. D. Magalhaes, L. S. Costa, G. P. Fidelis et al., "Anticoagulant, antioxidant and antitumor activities of heterofucans from the seaweed Dictyopteris delicatula," International Journal of Molecular Sciences, vol. 12, no. 5, pp. 3352-3365, 2011.

[30] E. Vamanu, "Biological activities of the polysaccharides produced in submerged culture of two edible Pleurotus ostreatus mushrooms," Journal of Biomedicine and Biotechnology, vol. 2012, Article ID 565974, 8 pages, 2012.

[31] D. Wang, L. Zeng, D. Li, and W. Pu, "Antioxidant activities of different extracts and homoisoflavanones isolated from the Polygonatum odoratum," Natural Product Research, vol. 27, no. 12, pp. 1111-1114, 2013.

[32] D. Ganjewala and A. K. Gupta, " Study on phytochemical composition, antibacterial and antioxidant properties of different parts of Alstonia scholaris Linn," Advanced Pharmaceutical Bulletin, vol. 3, no. 2, pp. 379-384, 2013.

[33] C. Qu, S. Yu, L. Luo, Y. Zhao, and Y. Huang, "Optimization of ulstrasonic extraction of polysaccharides from Ziziphus jujube Mill. by response surface methodology," Chemistry Central Journal, vol. 7, no. 1, pp. 160-166, 2013. 
[34] M. Dessi, A. Noce, P. Bertucci et al., "Atherosclerosis, dyslipidemia, and inflammation: the significant role of polyunsaturated fatty acids," ISRN Inflammation, vol. 2013, Article ID 191823, 13 pages, 2013.

[35] A. Kantachumpoo and A. Chirapart, "Components and antimicrobial activity of polysaccharides extracted from thai brown seaweeds," Kasetsart Journal (Natural Science), vol. 44, no. 2, pp. 220-233, 2010.

[36] H. Zhu, K. Sheng, E. Yan, J. Qiao, and F. Lv, "Extraction, purification and antibacterial activities of a polysaccharide from spent mushroom substrate," International Journal of Biological Macromolecules, vol. 50, no. 3, pp. 840-843, 2012. 

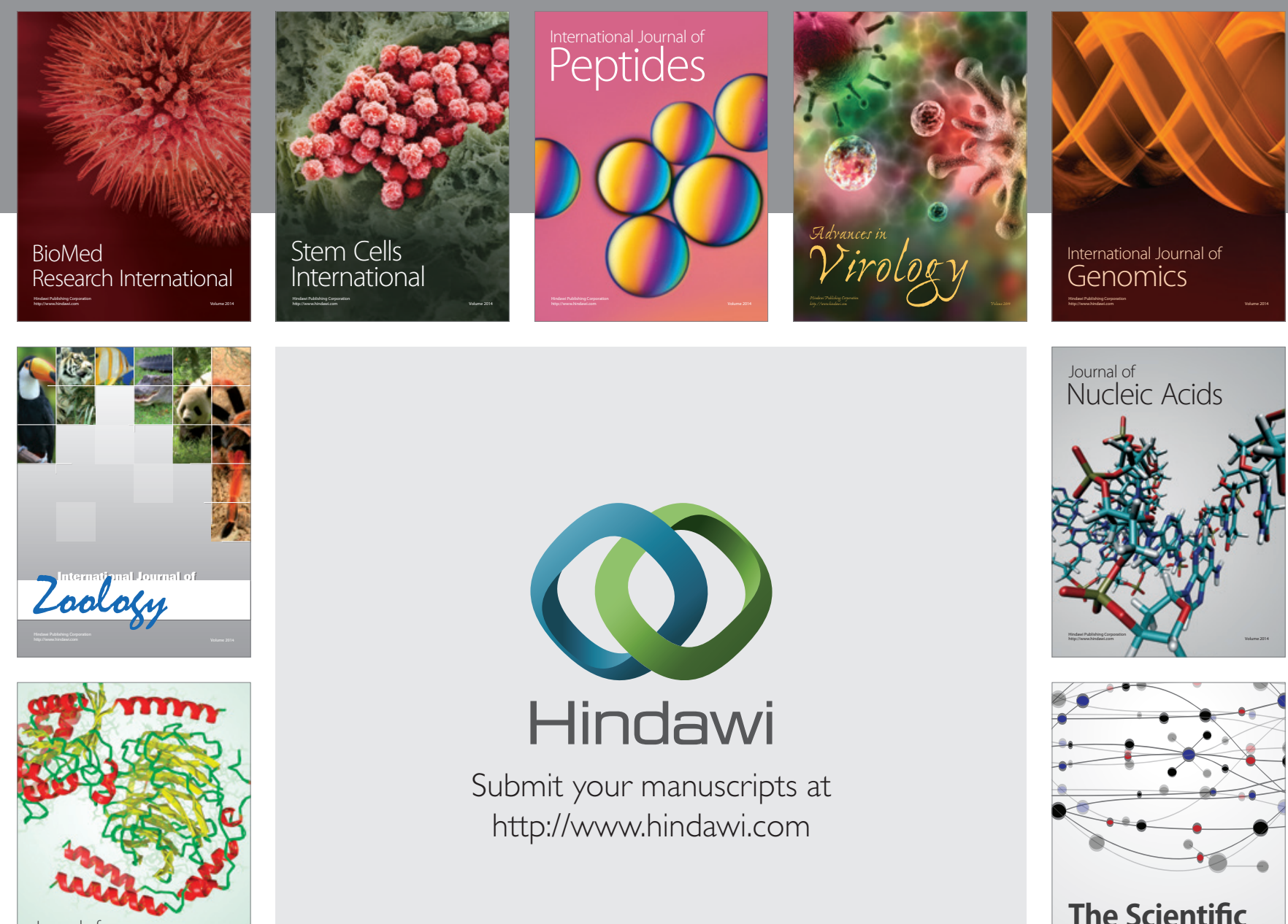

Submit your manuscripts at

http://www.hindawi.com

Journal of
Signal Transduction
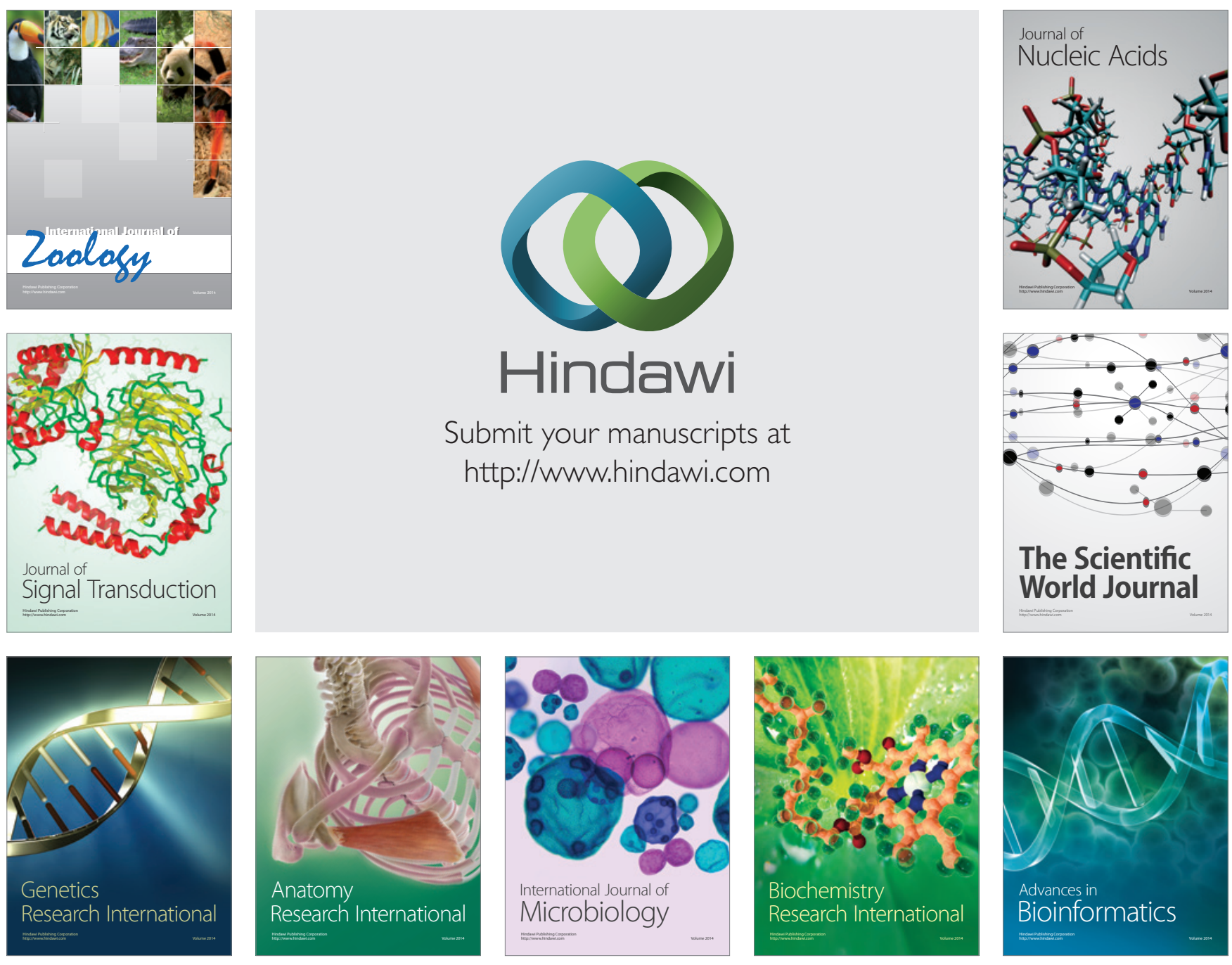

The Scientific World Journal
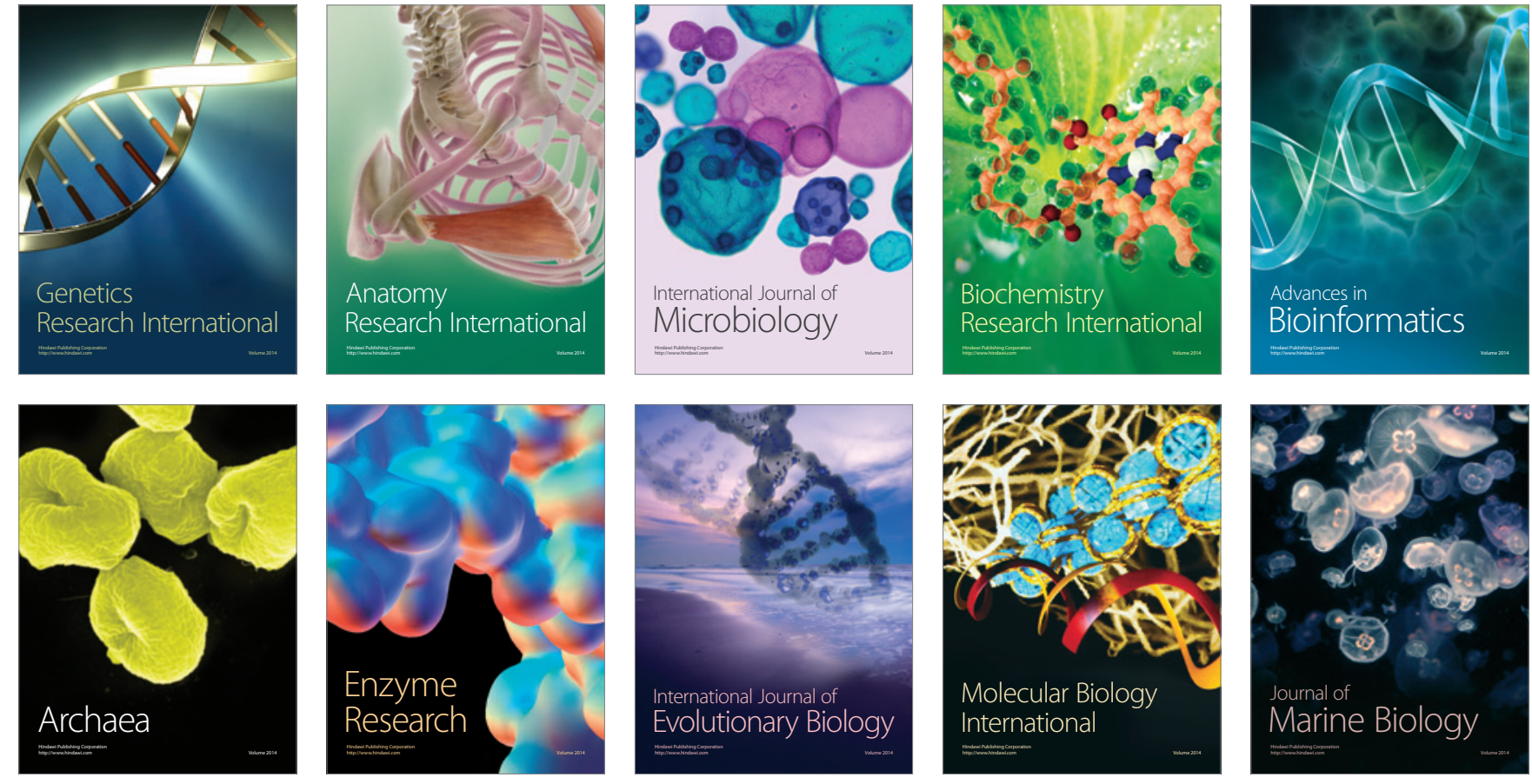